\title{
First retrieval of global water vapour column amounts from SCIAMACHY measurements
}

\author{
S. Noël, M. Buchwitz, and J. P. Burrows \\ Institute of Environmental Physics/Remote Sensing, University of Bremen, Germany \\ Received: 23 September 2003 - Published in Atmos. Chem. Phys. Discuss.: 11 November 2003 \\ Revised: 20 January 2004 - Accepted: 22 January 2004 - Published: 27 January 2004
}

\begin{abstract}
Global water vapour column amounts have been derived for the first time from measurements of the SCanning Imaging Absorption spectroMeter for Atmospheric CHartographY (SCIAMACHY) on the European environmental satellite ENVISAT. For this purpose, two different existing retrieval algorithms have been adapted, namely the Air Mass Corrected Differential Absorption Spectroscopy (AMC-DOAS) which was originally designed for GOME and the Weighting Function Modified Differential Absorption Spectroscopy (WFM-DOAS) which was mainly designed for the retrieval of $\mathrm{CH}_{4}, \mathrm{CO}_{2}$ and $\mathrm{CO}$ from SCIAMACHY near-infrared spectra. Here, both methods have been applied to SCIAMACHY's nadir measurements in the near-visible spectral region around $700 \mathrm{~nm}$.

Taking into account a systematic offset of $10 \%$, the results of these two methods agree within a scatter of about $\pm 0.5 \mathrm{~g} / \mathrm{cm}^{2}$ with corresponding SSM/I and ECMWF water vapour data. This deviation includes contributions from the temporal and spatial variability of water vapour. In fact, the mean deviation between the SCIAMACHY and the correlative data sets is much smaller: the SCIAMACHY total water vapour columns are typically about $0.15 \mathrm{~g} / \mathrm{cm}^{2}$ lower than the $\mathrm{SSM} / \mathrm{I}$ values and less than $0.1 \mathrm{~g} / \mathrm{cm}^{2}$ lower than corresponding ECMWF data. The SCIAMACHY water vapour results agree well with correlative data not only over ocean but also over land, thus showing the capability of SCIAMACHY to derive water vapour concentrations on the global scale.
\end{abstract}

\section{Introduction}

Water vapour is one of the most abundant atmospheric constituents and in fact the most important greenhouse gas. More than $99 \%$ of water vapour is located in the troposphere

Correspondence to: S. Noël

(stefan.noel@iup.physik.uni-bremen.de) where it significantly contributes to atmospheric chemistry, weather, and climate. Its large spatial and temporal variability makes water vapour a tracer for tropospheric changes and especially important for global models which aim to predict climate. The high relevance of water vapour has generated the need for global water vapour data. The main sources for these data are currently in-situ radio sonde, ground based or air borne measurements, space borne IR measurements, for example by the TIROS-N Operational Vertical Sounder (TOVS), and microwave soundings, for example by the Special Sensor Microwave Imager (SSM/I), and (recently) also MODIS. Additionally, water vapour total columns have been derived from Global Position System (GPS) observations (see e.g. Dai et al., 2002, and references therein). It has been shown by several studies (e.g. Noël et al., 1999, 2002b; Casadio et al., 2000; Maurellis et al., 2000; Lang et al., 2003; Wagner et al., 2003; Buchwitz et al., 2003) that measurements in the (near-)visible spectral region by the Global Ozone Monitoring Experiment (GOME) (see e.g. Burrows et al., 1999) provide an additional data source for global water vapour concentrations. An extended version of GOME, the SCanning Imaging Absorption spectroMeter for Atmospheric CHartographY (SCIAMACHY), has been successfully launched as part of the atmospheric chemistry payload of ENVISAT in March 2002.

In the current paper first SCIAMACHY water vapour results derived using two different retrieval algorithms are presented. These SCIAMACHY results are then compared with corresponding SSM/I and ECMWF (European Centre for Medium-Range Weather Forecasts) water vapour data.

\section{SCIAMACHY measurements}

The SCIAMACHY instrument is a national (German/Dutch/Belgian) contribution to ESA's European environmental satellite ENVISAT, which has been launched 
successfully in March 2002. SCIAMACHY determines the amount and distributions of a large number of atmospheric constituents by measuring Earthshine radiance and solar irradiance spectra simultaneously from the UV to the NIR (214-2380 nm) in nadir, limb and occultation geometry (see e.g. Bovensmann et al., 1999; Noël et al., 2002a, for details on the SCIAMACHY mission). After extensive tests to assure the correct functioning and performance of the instrument, SCIAMACHY entered nominal measurements mode in August 2002 (Bovensmann et al., 2002, 2003). Since then, mainly alternating nadir and limb measurements have been performed. Both $\mathrm{H}_{2} \mathrm{O}$ profiles and vertical column amounts are foreseen as operational SCIAMACHY data products, but due to problems in the operational data processing SCIAMACHY data could not be released to the public until now (September 2003). However, a limited amount of spectral data is already available to selected users. These data typically suffer from a non-optimal radiometric calibration, but as the results of the present paper show, this is not critical for the algorithms used here which rely on differential structures in the spectral region around $700 \mathrm{~nm}$. Nevertheless, it shall be noted that the water vapour results presented here are not based on the official SCIAMACHY Level 2 data products but have been derived from preliminary data.

\section{Retrieval methods}

\subsection{Air mass corrected DOAS}

First quantitative amounts of atmospheric water vapour vertical columns have been derived from cloud-free GOME measurements by Noël et al. (1999). The algorithm used is based on the well-known Differential Optical Absorption Spectroscopy (DOAS) approach (Perner and Platt, 1979; Burrows et al., 1999) which has been modified to handle effects arising from the strong differential absorption structures of water vapour.

The general features of this modified DOAS method are that (1) saturation effects arising from highly structured differential spectral features which are not resolved by the measuring instrument are accounted for, and (2) $\mathrm{O}_{2}$ absorption features are fitted in combination with $\mathrm{H}_{2} \mathrm{O}$ to determine an air mass correction factor which compensates to some degree for insufficient knowledge of the background atmospheric and topographic characteristics, like surface elevation and clouds.

The main equation of this method, which we call Air Mass Corrected (AMC-)DOAS, is given by:

$\ln \left(\frac{I}{I_{0}}\right)=P-a\left(\tau_{O_{2}}+c C_{V}^{b}\right)$

$I$ and $I_{0}$ are the measured earthshine radiance and solar irradiance, respectively. As in standard DOAS, all broadband contributions (resulting e.g. from Rayleigh and Mie scattering or surface albedo) are approximated by a polynomial $(P)$.

The term $\tau_{\mathrm{O}_{2}}$ denotes the $\mathrm{O}_{2}$ optical depth. $C_{V}$ is the vertical column amount of water vapour, $b$ and $c$ are spectral quantities describing the saturation effect and the absorption. Especially, $c$ contains the effective reference absorption cross section and the air mass factor. The term $\tau_{\mathrm{O}_{2}}$ is derived using radiative transfer calculations with and without $\mathrm{O}_{2}$. The parameters $b$ and $c$ are determined from radiative transfer calculations assuming different water vapour columns $C_{V}$ (see Noël et al., 1999, for further details). The scalar parameter $a$ is the above mentioned air mass correction factor. The quantities $\tau_{\mathrm{O}_{2}}, b$, and $c$ are determined from radiative transfer calculations performed for different atmospheric conditions and solar zenith angles. $C_{V}$ and $a$ are then derived from a non-linear fit.

The AMC-DOAS method is applied to the spectral region between $682 \mathrm{~nm}$ and $700 \mathrm{~nm}$ because both $\mathrm{O}_{2}$ and water vapour absorb in this region. They are the main absorbers in this spectral range, having slant optical depths of similar strength.

The AMC-DOAS method has been further developed to e.g. also allow for a retrieval over cloudy scenes (Noël et al., 2000, 2002b). It could be shown that the introduced cloud correction works well, but that it significantly increases the scatter in the data because the correction requires additional information on atmospheric and cloud properties which is typically not available at sufficiently high quality.

Therefore, it has to be accepted that the ability to derive concentrations of water vapour or other tropospheric gases from measurements in the the UV/Vis/NIR is generally limited by the opaqueness of clouds, although the method of air mass correction provides the possibility to retrieve meaningful $\mathrm{H}_{2} \mathrm{O}$ total columns also for partly cloudy scenes.

In fact, the derived air mass correction factor $a$ provides a good quality criterium for the retrieval if no cloud correction is performed. In the ideal case, i.e. if the atmospheric conditions used in the model calculations match the real conditions, the air mass correction factor should be 1 . In the presence of clouds, only the atmosphere above the clouds can be probed by the instrument, so the effective amount of both $\mathrm{O}_{2}$ and $\mathrm{H}_{2} \mathrm{O}$ seen by GOME or SCIAMACHY is smaller than the amount used in the model calculations. The air mass factor correction would then try to compensate for this. In this case $a$ would be smaller than 1. A too large deviation of the air mass correction from 1 is thus an indication that the conditions of the reference atmosphere differ too much from reality. In this case the retrieved $\mathrm{H}_{2} \mathrm{O}$ columns are considered to be unrealistic. In practice, it could be shown that data retrieved with air mass correction factors larger than 0.8 are reliable, even if the retrieval is only performed using one (tropical) background atmosphere (Noël et al., 2000). The choice of the model surface albedo is - like for most DOAStype methods - rather uncritical, although some additional errors my arise from this (see the error analysis below). 

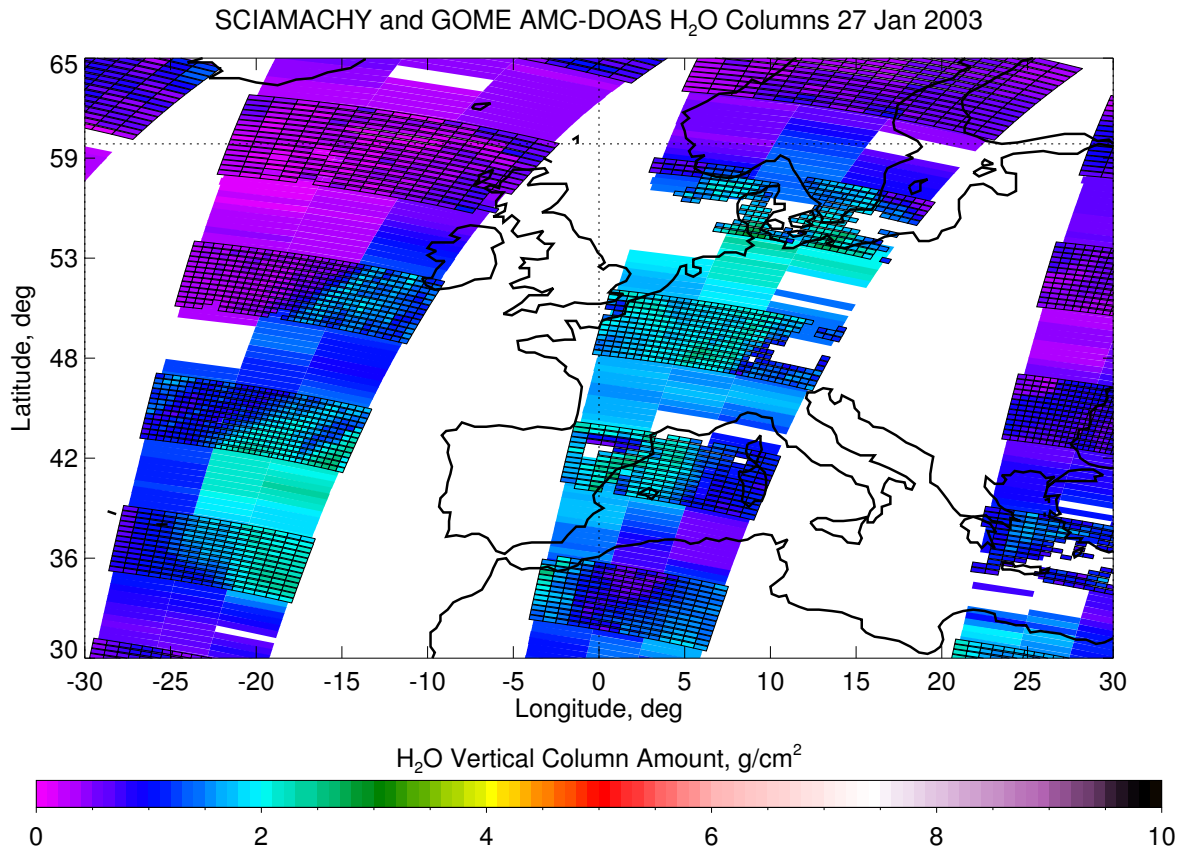

Fig. 1. SCIAMACHY and GOME water vapour total vertical columns for 27 January 2003 over Europe derived with the AMC-DOAS method (data from forward scans only). GOME measurements comprise three ground pixels for one forward scan (across track). The smaller SCIAMACHY ground pixels are marked by boxes.

Therefore, for the present study, all calculations have been performed using a cloud free tropical reference atmosphere assuming an albedo of 5\%, and results with an air mass correction factor smaller than 0.8 have been omitted. In addition, measurements performed at high solar zenith angles (larger than $88^{\circ}$ ) and backscan pixels have been excluded, the latter because of their lower spatial resolution. As GOME, the SCIAMACHY instrument can not see through clouds. However, because the ground pixel size of SCIAMACHY is typically much smaller than for GOME $(30 \mathrm{~km} \times 60 \mathrm{~km}$ compared to $40 \mathrm{~km} \times 320 \mathrm{~km}$ ), the probability for cloud-free scenes is much higher for SCIAMACHY, so less data have to be rejected. The improved spatial resolution of SCIAMACHY can be seen in Fig. 1.

For the present study, the GOME retrieval model has been adapted to handle SCIAMACHY data. The radiative transfer code SCIATRAN (Buchwitz et al., 2000b; Rozanov et al., 2002) has been used instead of its predecessor GOMETRAN (Rozanov et al., 1997), including the latest update of the HITRAN data base (Rothman et al., 2003; Coheur et al., 2003). Recent field tests have shown that especially the $4 v$ water vapour band around $720 \mathrm{~nm}$ used in the present study is well described by HITRAN (Sierk et al., 2003). Furthermore, the grid of solar zenith angles for radiative transfer calculations has been extended to $88^{\circ}$. A Gaussian slit function of full width at half maximum (FWHM) of $0.45 \mathrm{~nm}$ has been assumed to fold the highly resolved radiative transfer spectra down to the SCIAMACHY spectral resolution. Be- cause the SCIAMACHY slit function is close to undersampling at these wavelengths, the chosen value for the FWHM may need revision based on further analysis of in-flight spectra.

\subsection{WFM-DOAS}

WFM-DOAS (Buchwitz et al., 2000a; Buchwitz and Burrows, 2003) is based on linear least-squares fitting the logarithm of a linearised radiative transfer model plus a low-order polynomial to the logarithm of the ratio of a measured nadir radiance $I$ and solar irradiance spectrum $I_{0}$. The WFMDOAS equation can be written as follows:

$$
\begin{aligned}
& \ln \left(\frac{I}{I_{0}}\right)^{o b s}=\ln \left(\frac{I}{I_{0}}\right)^{\text {mod }} \\
& \quad+\left.\sum_{j=1}^{J} \frac{\partial \ln \left(I / I_{0}\right)^{\text {mod }}}{\partial V_{j}}\right|_{\bar{V}_{j}} \times\left(\hat{V}_{j}-\bar{V}_{j}\right)+P
\end{aligned}
$$

Here, $\ln \left(I / I_{0}\right)^{o b s}$ is the logarithm of the sun-normalised radiance as observed by SCIAMACHY. Terms with superscript $\bmod$ are the WFM-DOAS reference spectra which comprise the computed sun-normalised radiance and its derivatives (also called weighting functions). They correspond to an assumed model atmosphere, surface reflectivity, and viewing geometry, etc. The assumed columns of $\mathrm{H}_{2} \mathrm{O}$ and $\mathrm{O}_{2}$ are denoted $\bar{V}_{j}$ and the corresponding fit parameters 
Table 1. Deviation of water vapour columns retrieved by the AMC-DOAS algorithm from atmospheric spectra computed with SCIATRAN for different background atmospheres. The solar zenith angle is $50^{\circ}$, the surface albedo 0.05 in all cases.

\begin{tabular}{lrrrrr}
\hline $\begin{array}{l}\text { Background } \\
\text { Atmosphere }\end{array}$ & $\begin{array}{r}\mathrm{H}_{2} \mathrm{O} \text { Reference } \\
\text { Column }\left[\mathrm{g} / \mathrm{cm}^{2}\right]\end{array}$ & $\begin{array}{r}\text { Retrieved } \mathrm{H}_{2} \mathrm{O} \\
\text { Column }\left[\mathrm{g} / \mathrm{cm}^{2}\right]\end{array}$ & $\begin{array}{r}\text { Retrieved AMF } \\
\text { Correction Factor }\end{array}$ & $\begin{array}{r}\text { Relative Deviation } \\
\text { (Retr.-Ref.)/Ref. [\%] }\end{array}$ & $\begin{array}{r}\text { Abs. Deviation } \\
\text { (Retr.-Ref.) }\left[\mathrm{g} / \mathrm{cm}^{2}\right]\end{array}$ \\
\hline Tropical (TRO) & 4.18 & 4.18 & 1.00 & 0.0 & 0.00 \\
Mid-latitude summer (MLS) & 2.96 & 3.05 & 1.01 & 3.0 & 0.09 \\
Mid-latitude winter (MLW) & 0.89 & 0.85 & 1.06 & -4.7 & -0.04 \\
Sub-arctic summer (SAS) & 2.11 & 2.17 & 1.03 & 3.1 & 0.06 \\
Sub-arctic winter (SAW) & 0.42 & 0.38 & 1.08 & -8.6 & -0.04 \\
US-Standard (USS) & 1.43 & 1.47 & 1.04 & 3.0 & 0.04 \\
\hline
\end{tabular}

Table 2. Deviation of water vapour columns retrieved by the AMC-DOAS algorithm from atmospheric spectra computed with SCIATRAN for different surface albedos and a tropical background atmosphere. The solar zenith angle is $50^{\circ}$.

\begin{tabular}{lrrrrr}
\hline $\begin{array}{l}\text { Surface } \\
\text { Albedo }\end{array}$ & $\begin{array}{r}\mathrm{H}_{2} \mathrm{O} \text { Reference } \\
\text { Column }\left[\mathrm{g} / \mathrm{cm}^{2}\right]\end{array}$ & $\begin{array}{r}\text { Retrieved } \mathrm{H}_{2} \mathrm{O} \\
\text { Column }\left[\mathrm{g} / \mathrm{cm}^{2}\right]\end{array}$ & $\begin{array}{r}\text { Retrieved AMF } \\
\text { Correction Factor }\end{array}$ & $\begin{array}{r}\text { Relative Deviation } \\
\text { (Retr.-Ref.)/Ref. [\%] }\end{array}$ & $\begin{array}{r}\text { Abs. Deviation } \\
\text { (Retr.-Ref.) }\left[\mathrm{g} / \mathrm{cm}^{2}\right]\end{array}$ \\
\hline 0.05 & 4.18 & 4.18 & 1.00 & 0.0 & 0.00 \\
0.10 & 4.18 & 4.45 & 1.07 & 6.5 & 0.27 \\
0.30 & 4.18 & 4.67 & 1.13 & 11.7 & 0.49 \\
0.90 & 4.18 & 4.77 & 1.16 & 14.2 & 0.59 \\
\hline
\end{tabular}

$\hat{V}_{j}$. The derivatives refers to the change of the radiance due to changes (scaling) of pre-selected vertical profiles of $\mathrm{H}_{2} \mathrm{O}$ and $\mathrm{O}_{2}$.

In order to avoid time consuming on-line radiative transfer simulations, the reference spectra have been pre-calculated (look-up table approach). A single model atmosphere has been defined (US Standard Atmosphere plus tropospheric maritime and stratospheric background aerosol) and a single surface albedo (0.1). The tabulated reference spectra depend on solar zenith angle $\left(0^{\circ}-90^{\circ}\right.$ in steps of $\left.5^{\circ}\right)$, surface elevation $(0,1,2,3 \mathrm{~km})$ and water vapour column (scaling factors: $0.5,1.0,1.5,2.0,4.0$ ), in total 400 combinations. To account for the temperature dependence of the molecular absorption cross sections, the derivative of the radiance with respect to a temperature profile shift is included in the fit (omitted in Eq. (2) to simplify the notation). WFM-DOAS has been implemented as an iterative scheme, mainly to account for nonlinearities introduced by the high variability of atmospheric water vapour (initial guess: scaling factor 1.0, i.e. unchanged US Standard Atmosphere water vapour profile).

For similar reasons as described in the previous section, $\mathrm{O}_{2}$ has been included in the fit. The procedure as described above yields retrieved columns $\hat{V}_{\mathrm{H}_{2} \mathrm{O}}$ and $\hat{V}_{\mathrm{O}_{2}}$ (and their corresponding errors, see Buchwitz and Burrows, 2003). After the fit, the ratio $R_{\mathrm{O}_{2}}:=\bar{V}^{\prime} \mathrm{O}_{2} / \hat{V}_{\mathrm{O}_{2}}$ is computed, where $\bar{V}_{\mathrm{O}_{2}}^{\prime}$ is the $\mathrm{O}_{2}$ model column computed in a similar way as $\bar{V}_{\mathrm{O}_{2}}$ but for the actual average surface elevation of the SCIAMACHY ground pixel. To correct for air mass factor differences between the model and the real atmosphere (resulting from, e.g. partial cloud cover), the retrieved $\mathrm{H}_{2} \mathrm{O}$ columns are multiplied by $R_{\mathrm{O}_{2}}$. This means that each $\mathrm{H}_{2} \mathrm{O}$ column is actually divided by the simultaneously retrieved $\mathrm{O}_{2}$ column (and multiplied by scaling factor $\bar{V}^{\prime} \mathrm{O}_{2}$, which only depends on the average surface elevation of the ground pixel). Systematic errors which are common to the retrieved $\mathrm{H}_{2} \mathrm{O}$ and $\mathrm{O}_{2}$ columns will cancel when the ratio is computed (see error analysis given below). As a kind of quality measure and to limit the extent of the air mass factor correction, only retrievals with $R_{\mathrm{O}_{2}}$ larger than 0.7 and less than 1.3 are considered successful and are presented and discussed in this paper.

\section{Error Analysis}

\subsection{AMC-DOAS error analysis}

The AMC-DOAS method uses a single set of radiative transfer parameters $b, c$ and $\tau_{\mathrm{O}_{2}}$. These parameters have been computed for different solar zenith angles, but a fixed value of 0.05 for the surface albedo has been taken, and a tropical background atmosphere has been used. In this section, the influence of these two assumptions on the retrieval quality shall be assessed.

For this purpose, various radiance spectra for different atmospheric conditions and surface albedos have been modelled with SCIATRAN. The AMC-DOAS method has then been applied to these spectra, and the difference between the retrieved vertical water vapour column and the vertical water vapour column of the reference atmosphere has been 
Table 3. Retrieval errors determined by applying WFM-DOAS to simulated spectra generated using various model atmospheres. For detailed description of the last three columns see Sect. 4.2.1.

\begin{tabular}{lrrr}
\hline Atmosphere & $\begin{array}{r}\text { Error of uncorrected } \\
\mathrm{H}_{2} \mathrm{O} \text { column } \hat{V}_{\mathrm{H}_{2} \mathrm{O}} \\
\text { (Retr.-Ref.)/Ref. [\%] }\end{array}$ & $\begin{array}{r}\text { Error of } \\
\mathrm{O}_{2} \text { column } \hat{V}_{\mathrm{O}_{2}}\end{array}$ & $\begin{array}{r}\text { Error of }\left(\mathrm{O}_{2} \text { corrected) }\right. \\
\mathrm{H}_{2} \mathrm{O} \text { column } \\
\text { (Retr.-Ref.)/Ref. [\%] }\end{array}$ \\
\hline (Retr.-Ref.)/Ref. [\%]
\end{tabular}

Table 4. Vertical column retrieval errors resulting from aerosol variability and undetected subvisual cirrus clouds at $12 \mathrm{~km}(\mathrm{OD}$ means scattering optical depth). For detailed description of the last three columns see Sect. 4.2.1.

\begin{tabular}{lrrr}
\hline Aerosol/cloud scenario & $\begin{array}{r}\text { Error of uncorrected } \\
\mathrm{H}_{2} \mathrm{O} \text { column } \hat{\mathrm{V}}_{\mathrm{H}_{2} \mathrm{O}} \\
\text { (Retr.-Ref.)/Ref. [\%] }\end{array}$ & $\begin{array}{r}\text { Error of } \\
\mathrm{O}_{2} \text { column } \hat{V}_{\mathrm{O}_{2}} \\
\text { (Retr.-Ref.)/Ref. [\%] }\end{array}$ & $\begin{array}{r}\text { Error of }\left(\mathrm{O}_{2} \text { corrected) }\right. \\
\mathrm{H}_{2} \mathrm{O} \text { column } \\
\text { (Retr.-Ref.)/Ref. [\%] }\end{array}$ \\
\hline Aerosol: & & & \\
OPAC average continental & -2.07 & -1.78 & -0.30 \\
Enhanced aerosol in BL & -5.76 & 0.22 & -5.97 \\
No aerosol in atmosphere & -0.90 & -1.61 & 0.72 \\
Clouds: & & & -0.07 \\
Subvisual cirrus (OD 0.01) & -0.54 & -0.47 & -0.13 \\
Subvisual cirrus (OD 0.02) & -1.11 & -0.98 & -0.18 \\
Subvisual cirrus (OD 0.03) & -1.71 & -1.53 & \\
\hline
\end{tabular}

computed. All results in this section are valid for a solar zenith angle of $50^{\circ}$ and cloud-free conditions.

Table 1 shows the sensitivity of the AMC-DOAS method to different atmospheric conditions including different vertical profile shapes, namely for a tropical (TRO), sub-arctic summer/winter (SAS/SAW), mid-latitude summer/winter (MLS/MLW), and the US standard atmosphere (USS). The surface albedo has always been set 0.05 for these calculations.

For the tropical background atmosphere the exact water vapour column is derived showing the self-consistency of the AMC-DOAS method. Note that even the retrieved AMF correction factor is 1 in this case, as it should be. The maximum relative deviation between the retrieved and the reference water vapour column is about $9 \%$, occurring for the SAW reference atmosphere. This is not surprising as the SAW atmosphere has the lowest $\mathrm{H}_{2} \mathrm{O}$ contents and is thus the furthest away from the tropical reference atmosphere assumed by AMC-DOAS. In fact, the absolute deviation is in all cases smaller than $0.1 \mathrm{~g} / \mathrm{cm}^{2}$, showing that the sensitivity of the AMC-DOAS method to different atmospheric background conditions is considerably low.

The sensitivity to the surface albedo is somewhat higher, as can be seen from Table 2 which lists the results of the AMC-DOAS retrieval for albedos higher than the assumed
0.05 (which is about valid for ocean areas), namely 0.1 (which is the one assumed by the WFM-DOAS method), 0.3 (typical for land surface), and 0.9 (corresponding to ice). Except for the standard 0.05 albedo which shows (as mentioned before) self-consistency, the retrieved column for the other albedos is always too large, and the error increases with the albedo. The maximum relative deviation is about $14 \%$, corresponding to an absolute deviation of about $0.6 \mathrm{~g} / \mathrm{cm}^{2}$. However, this deviation occurs for a surface albedo of 0.9 which may not be too realistic for a (cloud-free) tropical atmosphere. Nevertheless, the expected deviation over land (albedo 0.3 ) is only slightly smaller (about $12 \%, 0.5 \mathrm{~g} / \mathrm{cm}^{3}$ ). It is planned to reduce this albedo dependence in future versions of the AMC-DOAS algorithm by using different parameter sets for different surface conditions.

An additional - maybe even the largest - error source for the retrieval are clouds. In general, the atmosphere below the clouds can not be seen by SCIAMACHY, resulting in a decreased absorption depth for all tropospheric constituents compared to the cloud-free case. The AMC-DOAS method principally accounts for this effect by the derived air mass correction factor, which is usually smaller than 1 for the cloudy case. Clouds may therefore partly compensate the effect of higher albedos, for which the air mass correction factors are usually larger than 1 as can be seen from Table 2 . A 
Table 5. Vertical column retrieval errors as a function of surface albedo. For an albedo of 0.1 the errors are (nearly) zero because the reference spectra are calculated for albedo 0.1 (note that the small error of $-0.01 \%$ for oxygen results from wavelength interpolation of the reference spectra). For detailed description of the last three columns see Sect. 4.2.1.

\begin{tabular}{|c|c|c|c|}
\hline Albedo & $\begin{array}{l}\text { Error of uncorrected } \\
\mathrm{H}_{2} \mathrm{O} \text { column } \hat{V}_{\mathrm{H}_{2} \mathrm{O}} \\
\text { (Retr.-Ref.)/Ref. [\%] }\end{array}$ & $\begin{array}{r}\text { Error of } \\
\mathrm{O}_{2} \text { column } \hat{V}_{\mathrm{O}_{2}} \\
\text { (Retr.-Ref.)/Ref. [\%] }\end{array}$ & $\begin{array}{r}\text { Error of }\left(\mathrm{O}_{2} \text { corrected }\right) \\
\mathrm{H}_{2} \mathrm{O} \text { column } \\
\text { (Retr.-Ref. }) / \text { Ref. [\%] }\end{array}$ \\
\hline 0.03 & -23.40 & -18.76 & -5.71 \\
\hline 0.05 & -13.10 & -10.57 & -2.83 \\
\hline 0.10 & 0.00 & -0.01 & 0.01 \\
\hline 0.20 & 10.45 & 8.45 & 1.84 \\
\hline 0.30 & 15.37 & 12.37 & 2.67 \\
\hline
\end{tabular}

quantitative estimation of the influence of clouds using simulated data is difficult because of the various types of clouds and the usually inhomogeneous spatial distribution (both horizontally and vertically) within the instrument field of view. At present, a statistical analysis of a comparison with correlative measurements (as described in Sect. 5.4) seems to be a more appropriate approach.

\subsection{WFM-DOAS error analysis}

The fast look-up table approach described in Sect. 3.2 introduces errors. In addition, there are errors resulting from parameters that influence the radiative transfer but are not retrieved by WFM-DOAS, such as aerosols and clouds. In the following, an initial error analysis of the currently implemented version of WFM-DOAS is presented. For this purpose, simulated nadir spectra have been generated with a radiative transfer model for various conditions, such as different model atmospheres and surface albedos. If not stated otherwise, the results shown in this section are valid for a solar zenith angle of $50^{\circ}$ and albedo 0.1 .

\subsubsection{Sensitivity to vertical profiles}

The currently implemented look-up table has been generated assuming vertical profiles of pressure, temperature and trace gas and oxygen volume mixing ratios corresponding to the US Standard Atmosphere. In order to estimate the vertical column retrieval error resulting from applying WFM-DOAS to different atmospheres, simulated spectra for several model atmospheres have been generated. The results are shown in Table 3.

The second column of Table 3 shows the relative difference between the uncorrected $\mathrm{H}_{2} \mathrm{O}$ column, $\hat{V}_{\mathrm{H}_{2} \mathrm{O}}$ (see Eq. 2), and the known $\mathrm{H}_{2} \mathrm{O}$ column of the model atmosphere. The third column shows the error of $\hat{V}_{\mathrm{O}_{2}}$. The last column shows the error of the WFM-DOAS retrieved $\mathrm{H}_{2} \mathrm{O}$ columns discussed in this paper (i.e., after $\mathrm{O}_{2}$ correction factor $R_{\mathrm{O}_{2}}$ has been applied to $\hat{V}_{\mathrm{H}_{2} \mathrm{O}}$, see Sect. 3.2). For a given surface elevation $R_{\mathrm{O}_{2}}$ is a constant divided by the retrieved $\mathrm{O}_{2}$ column. Therefore this error is identical with the error of the ratio of the retrieved $\mathrm{H}_{2} \mathrm{O}$ and $\mathrm{O}_{2}$ column, i.e., with the error of $\hat{V}_{\mathrm{H}_{2} \mathrm{O}} / \hat{V}_{\mathrm{O}_{2}}$. This error given in the last column has been computed from the errors given in the two previous columns by: $c:=((1+a / 100) /(1+b / 100)-1) \times 100$, where $a$ denotes the percentage error of $\hat{V}_{\mathrm{H}_{2} \mathrm{O}}$ and $b$ denotes the percentage error of $\hat{V}_{\mathrm{O}_{2}}$ (note that $c \approx a-b$ ). For the US-Standard atmosphere the errors are (nearly) zero because this is the WFM-DOAS reference atmosphere (note that the small error of $-0.01 \%$ for oxygen results from wavelength interpolation of the reference spectra). This demonstrates the self-consistency of the WFM-DOAS method. The retrieval errors mainly reflect the difference in temperature and water vapour profiles of the various atmospheres compared to the US Standard (USS) reference atmosphere (temperatures at sea level in K: USS 288.1, SAW 257.2, TRO 299.7; $\mathrm{H}_{2} \mathrm{O}$ columns: see Table 1). To deal with temperature variability the derivative with respect to a temperature profile shift is included in the fit. To deal with water vapour variability the reference spectra have been computed for several water vapour profiles (columns). As can be seen, the error on the retrieved water vapour column is below $5 \%$. For retrievals without allowing for a temperature shift this error could exceed $10 \%$.

Note that for this study the errors given in the last column of the tables presented in this section are the most relevant.

\subsubsection{Sensitivity to aerosols and subvisual cirrus clouds}

Aerosols and clouds mainly scatter but also absorb solar radiation. A large fraction of the water vapour molecules is situated in the lowest kilometres of the atmosphere, i.e., in a region where clouds and aerosols are present in extremely variable type and concentration. The WFM-DOAS reference spectra look-up table used in this study has been generated using a single aerosol scenario only. It is based on the aerosol parameterisation also implemented in the radiative transfer model MODTRAN (Kneizys et al., 1996) and is based on Shettle and Fenn (1979). This (default) scenario can be characterised as follows: Maritime aerosol in the boundary layer (BL), tropospheric visibility and relative humidity $23 \mathrm{~km}$ and $80 \%$, respectively, and background stratospheric and normal mesospheric conditions. Aerosol scattering and absorption 
vertical optical depth are listed in Table 3 of Buchwitz and Burrows (2003). To a first approximation aerosols increase or decrease the overall (i.e., spectrally broadband) level of solar radiation scattered back to space. This effect is taken into account by the polynomial included in Eq. (2). However, aerosols also determine the relative depth of absorption lines by influencing the (average) photon path.

The retrieval error due to aerosol has been estimated by defining several aerosol scenarios (including two rather extreme ones: (i) extreme aerosol loading of the boundary layer and (ii) no aerosols in atmosphere). The "OPAC average continental" aerosol scenario (Hess et al., 1998) and radiative transfer simulations differ from the default scenario used for the reference spectra in various aspects (Mie phase function instead of Henyey-Greenstein approximation, scattering and extinction profiles). "OPAC average continental" aerosol consists of a mixture of "water soluble aerosol" (small particles mainly originating from gas-to-particle conversion), soot, and "insoluble aerosol" (dust). The "Enhanced aerosol in boundary layer (BL)" scenario contains urban aerosol in the BL with a visibility as low as $2 \mathrm{~km}$ and a high relative humidity of $99 \%$. For the "No aerosol in atmosphere" scenario the aerosols have been entirely "switched off" in the radiative transfer simulation. Table 4 shows that the error of the water to oxygen column ratio (last column) is typically below $1 \%$, except for the scenario with extremely enhanced aerosol in the planetary boundary layer where the error can be as large as $6 \%$. The main reason why the systematic errors on the uncorrected water vapour column (second column) and the oxygen column (third column) are not identical (and, therefore, do not perfectly cancel when the error on the column ratio is computed) is that the profile shapes are rather different.

Realistic errors introduced by clouds are difficult to estimate using simulated spectra (because strictly speaking the full three dimensional structure of clouds covering only a part of the ground pixel has to be considered). For this study we have limited ourselves to estimate the vertical column retrieval error resulting from subvisual cirrus clouds. These clouds have been modelled in this study as a scattering layer of $1 \mathrm{~km}$ vertical extent centered at $12 \mathrm{~km}$. The assumed scattering vertical optical depths were $0.01,0.02$, and 0.03 (independent of wavelength). Table 4 shows that such a scattering layer near the tropopause is expected to lead to an underestimation of the retrieved uncorrected water vapour columns (shielding of the troposphere lying underneath) by up to nearly $2 \%$. The oxygen column errors are nearly identical with the uncorrected water vapour column errors. Therefore, the error of the column ratio is significantly smaller (below $0.2 \%$ ) than the error of the uncorrected column.

\subsubsection{Sensitivity to surface albedo}

The WFM-DOAS look-up table used in this study has been generated assuming a constant (Lambertian) albedo of 0.1 .
To a first approximation albedo affects the overall (i.e., spectrally broadband) level of solar radiation scattered back to space. This effect is taken into account by the polynomial included in Eq. (2). However, as aerosols, the albedo also influences the relative depth of absorption lines.

As shown in Table 5 the errors of the $\mathrm{O}_{2}$ corrected $\mathrm{H}_{2} \mathrm{O}$ columns are below $6 \%$ for albedos between 0.03 and 0.3 .

\subsubsection{Other error sources}

In this section three additional errors are quantified which are related to the (rather sparse) grid selected for the WFMDOAS reference spectra look-up table: solar zenith angle interpolation, scan angle correction, and surface elevation (pressure). Note that these errors can be reduced relatively easily, e.g., by extending the look-up table and/or by implementing a better interpolation scheme.

The WFM-DOAS look-up table used in this study has been generated for a range of solar zenith angles from 0 to $90^{\circ}$ in steps of $5^{\circ}$. These spectra are (linearly) interpolated to the solar zenith angle of the measurement. The resulting retrieval error is rather small (e.g. less than $0.02 \%$ for a solar zenith angle of $52.4^{\circ}$ ).

The look-up table has been generated for exact nadir observation only, neglecting the $\pm 30^{\circ}$ scan around the nadir direction. The columns as determined by the fit are corrected using a simple geometrical approximation Buchwitz et al. (2000a) to account for the enhancement of the depth of absorption lines due to the slant path viewing geometry. The currently implemented correction scheme may result in errors of the water vapour to oxygen column ratio of less than $1 \%$. For the uncorrected water column the error might be as large as $6.5 \%$ for the most eastward and westward ground pixels. For oxygen the error is nearly the same and, therefore, the error of the water to oxygen ratio is close to zero.

The look-up table has been generated for a limited number of surface elevations (or surface pressures), covering the range $0-3 \mathrm{~km}$ in steps of $1 \mathrm{~km}$. A simple next neighbour approach is currently implemented in order to select the reference spectra for a given ground pixel. This results in retrieval errors of $2-3 \%$ for the water vapour to oxygen column ratio.

There are many other potential sources of retrieval errors which are not covered in this study (e.g., calibration errors). A potentially important error source which is difficult to quantify are the spectroscopic data (HITRAN 2000 has been used for this study including all updates available until March 2003 and taking into account the pressure shift of line transitions not considered in earlier versions of the look-up table). Retrieval errors on the order of a few percent can be expected due to, e.g. line intensity uncertainties. 
SCIAMACHY AMC-DOAS $\mathrm{H}_{2} \mathrm{O}$ Fit Results (27 Jan 2003 10:22)
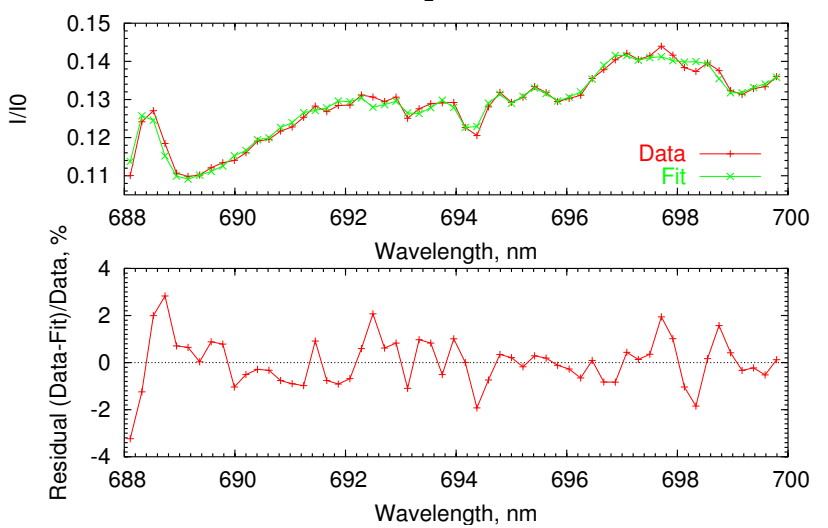

Fig. 2. Example for a fit using the AMC-DOAS method (nadir readout 2568 of orbit 4757 on 27 January 2003 10:22). Top: Sunnormalised SCIAMACHY data and fitted spectrum. Bottom: Corresponding residual.

\section{Results}

\subsection{Fit results}

Because of the currently limited amount of available data the present study concentrates on the analysis of SCIAMACHY measurements taken on 27 January 2003 as this is one of the first days for which almost all measured spectra are available in consolidated product files. However, other days have been analysed, too, yielding similar results. Since the solar reference spectra contained in the operational products are currently of limited quality, the analysis uses an elevation diffuser sun reference spectrum measured on 23 January 2003, which has been derived using an improved calibration procedure (J. Frerick, ESA, personal communication).

Note that it was not necessary to include a "shift and squeeze" correction for the spectral calibration in the fitting process, as it could be verified that such a correction has no significant influence on the retrieval results. Therefore, it has been omitted for processing speed reasons.

First retrieval results using the AMC-DOAS algorithm with SCIAMACHY data revealed systematically about $10 \%$ lower water vapour columns derived from SCIAMACHY data in comparison with corresponding SSM/I data over ocean. This is consistent with the results of the WFM-DOAS method. To compensate for this systematic effect, all AMCDOAS and WFM-DOAS water vapour columns presented in this paper have been multiplied by 1.1. The reason for this systematic under-estimation by SCIAMACHY is currently unclear. Since different algorithms (both AMC-DOAS and WFM-DOAS) derive approximately the same offset, errors in the algorithms or their implementation seem to be unlikely. The following possible systematic error sources are currently under discussion:
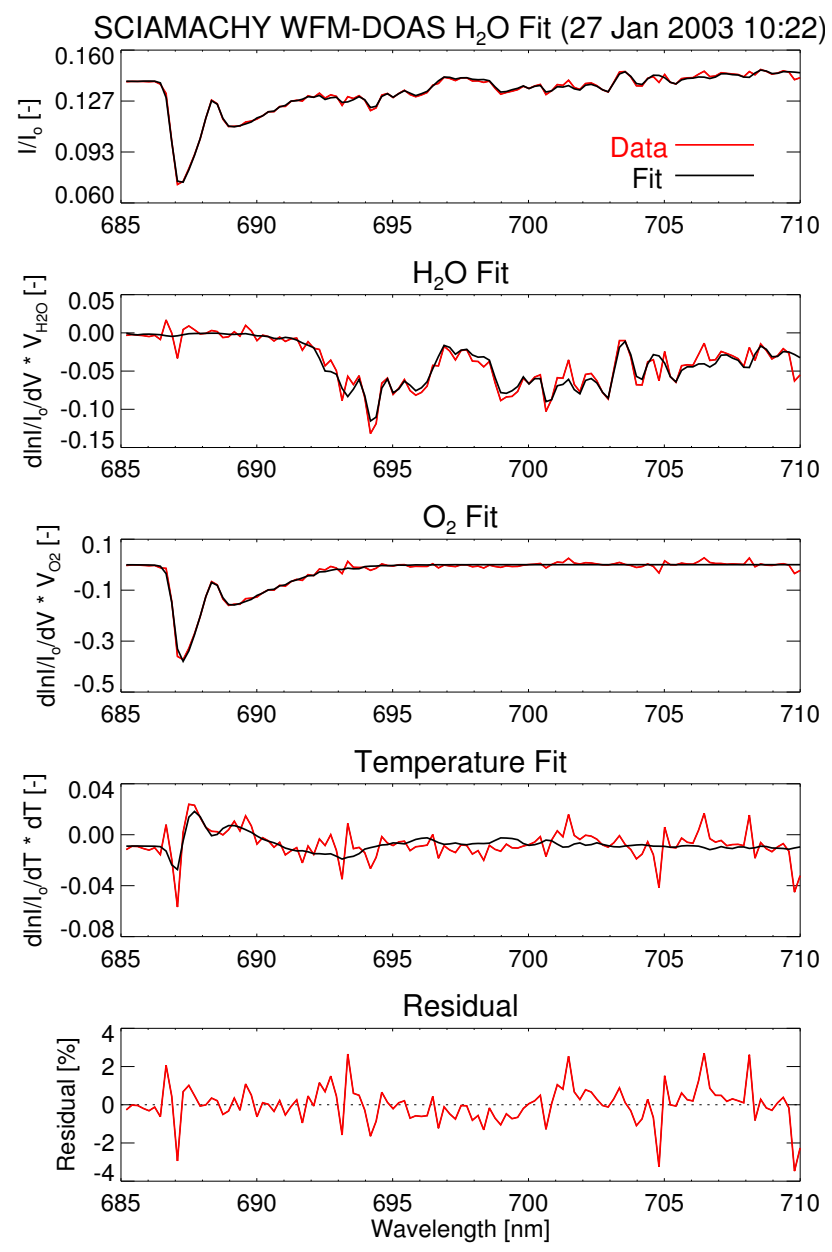

Fig. 3. Typical example of a WFM-DOAS fit. Top panel: Sun-normalised radiance as measured by SCIAMACHY (red) and WFM-DOAS model after the fit (black). Following three panels: (i) $\mathrm{H}_{2} \mathrm{O}$ fit: fitted (i.e. scaled) $\mathrm{H}_{2} \mathrm{O}$ weighting function (black) and $\mathrm{H}_{2} \mathrm{O}$ fit residuum (red). The $\mathrm{H}_{2} \mathrm{O}$ fit residuum is defined as the sum of the scaled $\mathrm{H}_{2} \mathrm{O}$ weighting function plus the fit residuum (i.e. the difference between measurement and model, see bottom panel). Retrieved column: $1.54 \pm 0.07 \mathrm{~g} / \mathrm{cm}^{2}$. (ii) $\mathrm{O}_{2}$ fit: $5.00 \times 10^{24}$ molecules $/ \mathrm{cm}^{2} \pm 1.8 \%$. (iii) Temperature fit: retrieved temperature profile shift: $24 \pm 4 \mathrm{~K}$. Bottom panel: relative difference measurement-model (RMS: 0.96\%).

1. Systematic errors arising from the currently insufficient radiometric calibration of SCIAMACHY. This can be assessed as soon as re-processed data are available (probably mid of 2004).

2. An error due to insufficient knowledge of the instrument slit function. This needs further investigation using inflight monitoring measurements.

3. Potential errors in the spectral data base (absolute cross sections). This error is considered to be small, because the water vapour band used seems to be well described 

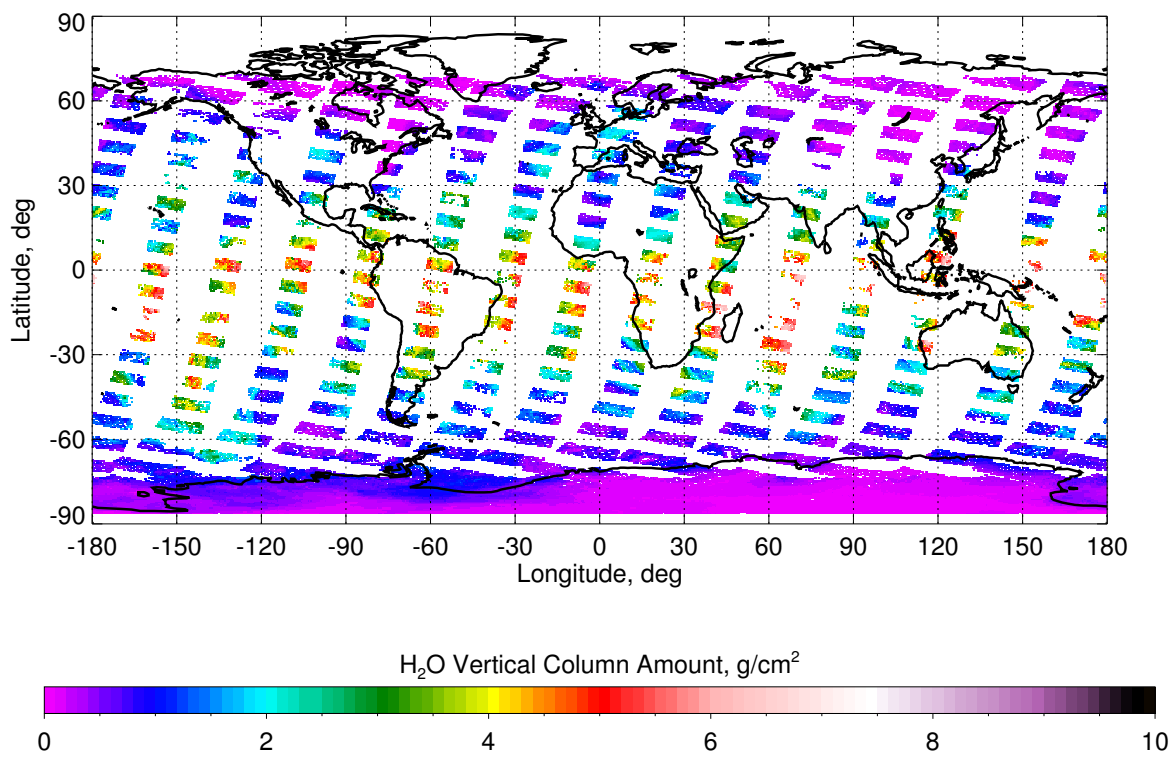

Fig. 4. Gridded SCIAMACHY water vapour total vertical columns for 27 January 2003 derived with the AMC-DOAS method.

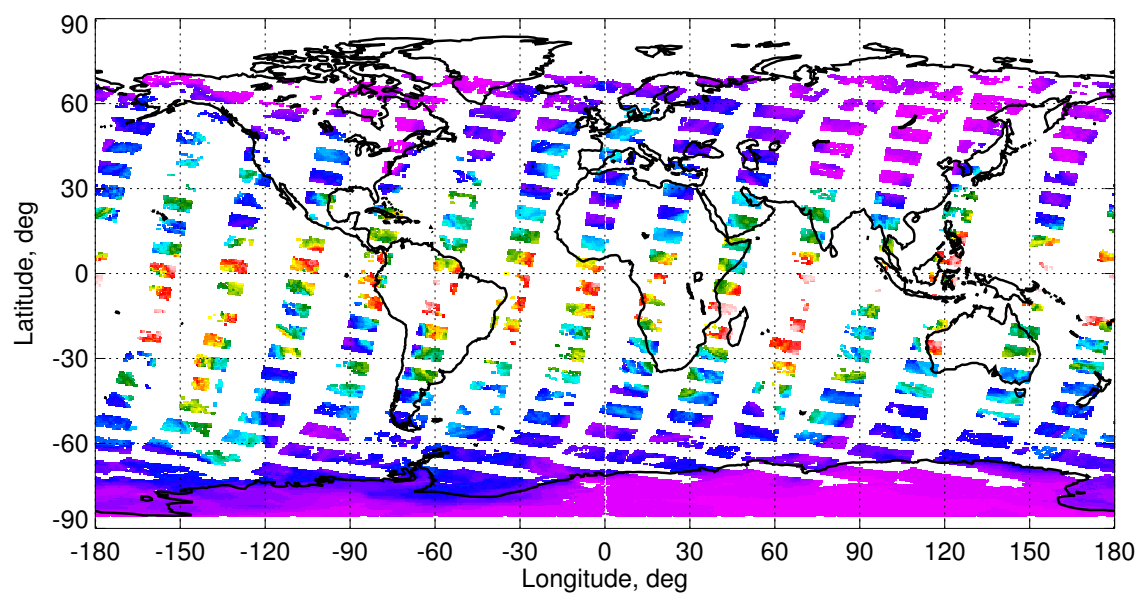

$\mathrm{H}_{2} \mathrm{O}$ Vertical Column Amount, $\mathrm{g} / \mathrm{cm}^{2}$

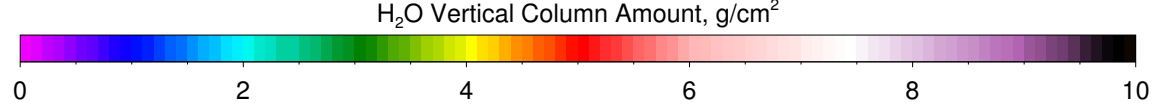

Fig. 5. Gridded SCIAMACHY water vapour total vertical columns for 27 January 2003 derived with the WFM-DOAS method.

by HITRAN. Nevertheless, transferring the algorithm to other spectral regions where water vapour absorbs (further in the infrared) may give more information on this contribution.

4. Systematic effects of surface albedo and clouds (see also error analysis in Sect. 4). Especially this point requires further studies.
Figure 2 shows a typical fit result of the AMC-DOAS method for one individual nadir measurement. The solar zenith angle for this measurement is about $43^{\circ}$, the retrieved column $1.85 \pm 0.25 \mathrm{~g} / \mathrm{cm}^{2}$. The measured data are reproduced quite well, with an average residual of about $2 \%$. The WFM-DOAS method essentially yields the same results for the residual (see Fig. 3), although the retrieved column is actually lower $\left(1.54 \pm 0.07 \mathrm{~g} / \mathrm{cm}^{2}\right)$. 


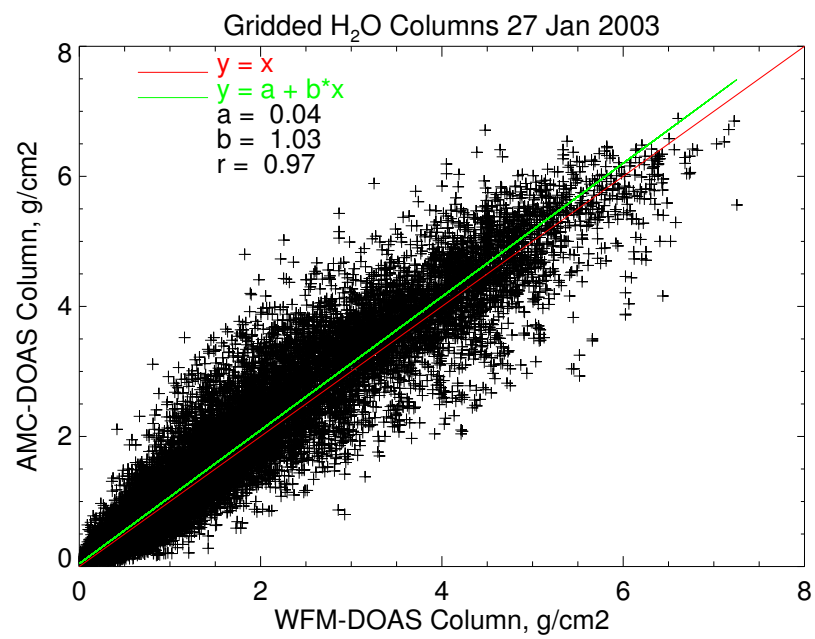

Fig. 6. Correlation between gridded SCIAMACHY/AMCDOAS and SCIAMACHY/WFM-DOAS water vapour total vertical columns for 27 January 2003. Red line: 1:1 correlation. Green line: Linear fit. The resulting linear Pearson's correlation coefficient $r$ is also specified.

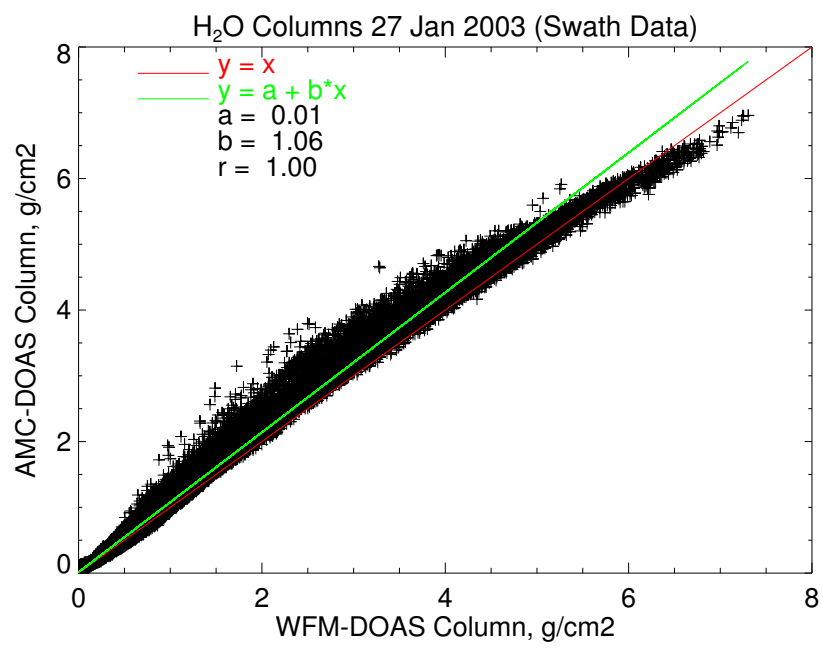

Fig. 7. Correlation between SCIAMACHY/AMC-DOAS and SCIAMACHY/WFM-DOAS water vapour total vertical columns for 27 January 2003 (swath data). Red line: 1:1 correlation. Green line: Linear fit. The resulting linear Pearson's correlation coefficient $r$ is also specified.

The complete data sets derived for 27 January 2003 by the AMC-DOAS and WFM-DOAS methods are displayed in Figs. 4 and 5. The data have been gridded to $0.5^{\circ} \times 0.5^{\circ}$ to facilitate a comparison with SSM/I and ECMWF data (see below). Note that the regular gaps between blocks of nadir measurements along the orbits are caused by SCIAMACHY's standard measurement mode involving alternating limb and nadir measurements. Taking this into account, it can be seen that not many data are rejected by the inher- ent quality check of both retrieval algorithms. In fact, both algorithms reject data in the same areas, mainly within the tropical regions where usually extended cloud coverage is expected. In addition, the AMC-DOAS quality check rejects data over high surface altitude regions, like the Himalaya, because in this case air mass correction can not compensate for the largely different atmospheric conditions. The WFMDOAS methods considers different surface elevations (using an appropriate data base) and thus has less problems here.

The direct correlation between the two methods (see Fig. 6) shows an almost perfect agreement (linear Pearson's correlation coefficient $r=0.97$ ), although the scatter of the data is high. As can be seen from the comparison of ungridded swath data in Fig. 7 most of this scatter is caused by gridding. For the ungridded data the correlation is perfect (1.0), although there seem to be systematic deviations depending on the water vapour column. Most likely, these deviations are caused by the different retrieval methods: The AMC-DOAS method only uses a tropical reference atmosphere, whereas the WFM-DOAS method relies on a large input data base for surface elevation, etc., and retrieves not only the water vapour column in an iterative way, but other atmospheric parameters as well $\left(\mathrm{O}_{2}\right.$ column, temperature profile shift). Therefore, the observed differences are not surprising.

\subsection{Comparison with SSM/I data}

In contrast to SCIAMACHY, the SSM/I instrument is capable to measure under all illumination conditions, but only over water surface. For the comparison with SCIAMACHY data measurements of the SSM/I instrument onboard DMSP-14 during the descending part of the orbit have been selected, because in this case the difference in local time between SCIAMACHY and SSM/I are smallest (ENVISAT has an equatorial crossing time of of 10:00 LT whereas DMSP-14 crosses the equator at about 08:00 LT).

Figure 8 shows the gridded total precipitable water columns derived from SSM/I measurements on 27 January 2003. Clearly, the same water vapour structures as in the SCIAMACHY data can be seen. The correlation between SSM/I and SCIAMACHY water vapour is for both methods (AMC-DOAS, see Fig. 9, and WFM-DOAS, see Fig. 10) quite good. At the lower edge of the plots, SSM/I data show some extraordinarily high columns which are probably due to water regions in the northern area covered with ice which have not been masked out.

\subsection{Comparison with ECMWF data}

SSM/I data are only available over open water. To assess the quality of the derived SCIAMACHY water vapour columns also over land a comparison with assimilated global water vapour data provided by the European Centre for MediumRange Weather Forecasts (ECMWF) has been performed. 

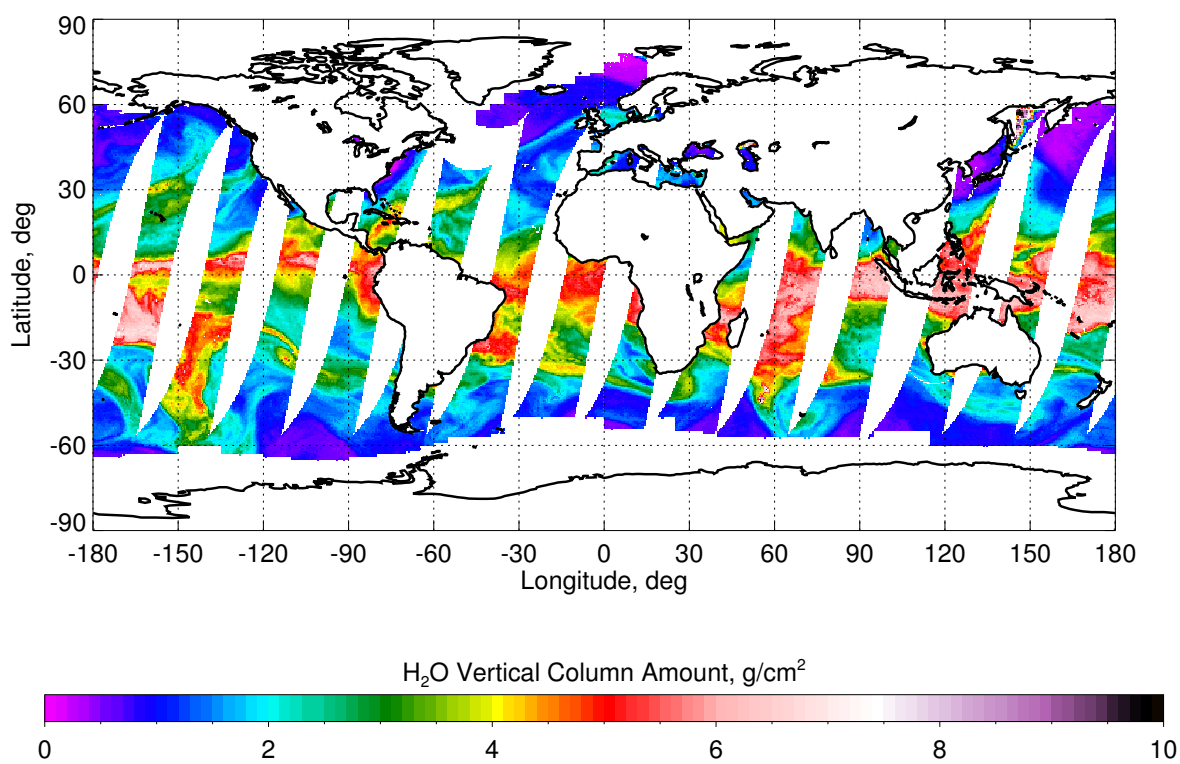

Fig. 8. DMSP-F14 SSM/I water vapour total vertical columns for 27 January 2003 (descending orbit part only).

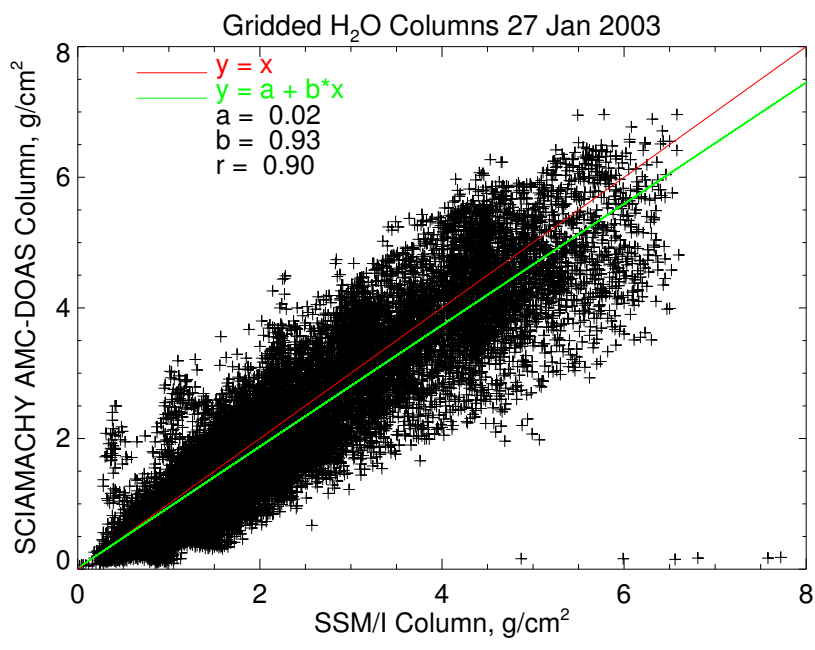

Fig. 9. Correlation between SSM/I and SCIAMACHY/AMCDOAS water vapour total vertical columns for 27 January 2003. Only the descending part of the SSM/I data has been used. Red line: 1:1 correlation. Green line: Linear fit. The resulting linear Pearson's correlation coefficient $r$ is also specified.

Note that the ECMWF data at least partly rely on SSM/I data, such that no large differences are expected over ocean areas.

The data set of analysed meteorological fields provided by ECMWF that has been used for this study comprises geopotential height, temperature, pressure, and specific humidity on a $1.5^{\circ} \times 1.5^{\circ}$ latitude/longitude grid on 60 model altitude levels. From these data the water vapour column in $\mathrm{g} / \mathrm{cm}^{2}$

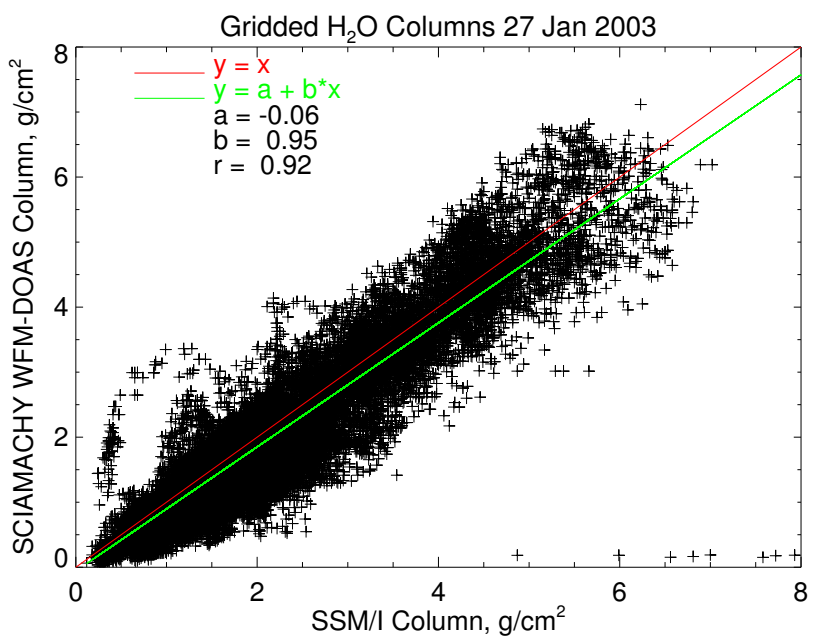

Fig. 10. Correlation between SSM/I and SCIAMACHY/WFMDOAS water vapour total vertical columns for 27 January 2003. Only the descending part of the SSM/I data has been used. Red line: 1:1 correlation. Green line: Linear fit. The resulting linear Pearson's correlation coefficient $r$ is also specified.

has been computed for each grid point by numerical integration. For each day a daily average column field has been calculated from the original six-hourly fields (0:00, 6:00, 12:00, 18:00, and 24:00 UTC). These data have then been remapped on a $0.5^{\circ} \times 0.5^{\circ}$ latitude/longitude grid by assigning to each grid point the corresponding value of its lower resolution grid box, thereby avoiding any interpolation. 


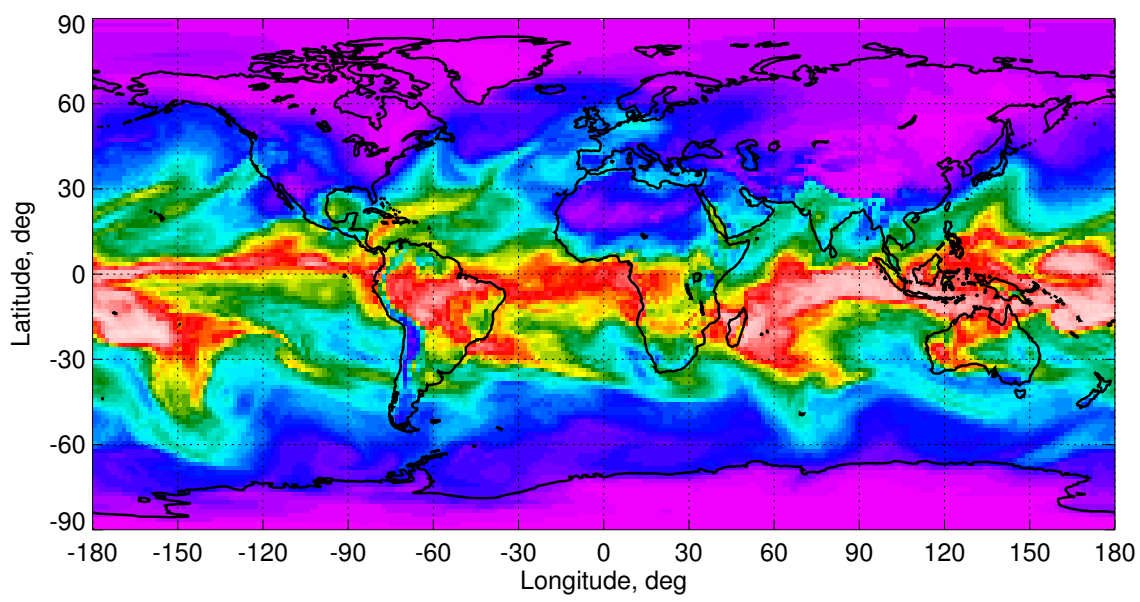

$\mathrm{H}_{2} \mathrm{O}$ Vertical Column Amount, $\mathrm{g} / \mathrm{cm}^{2}$

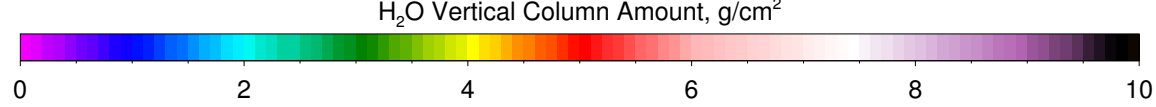

Fig. 11. ECMWF water vapour total vertical columns for 27 January 2003.

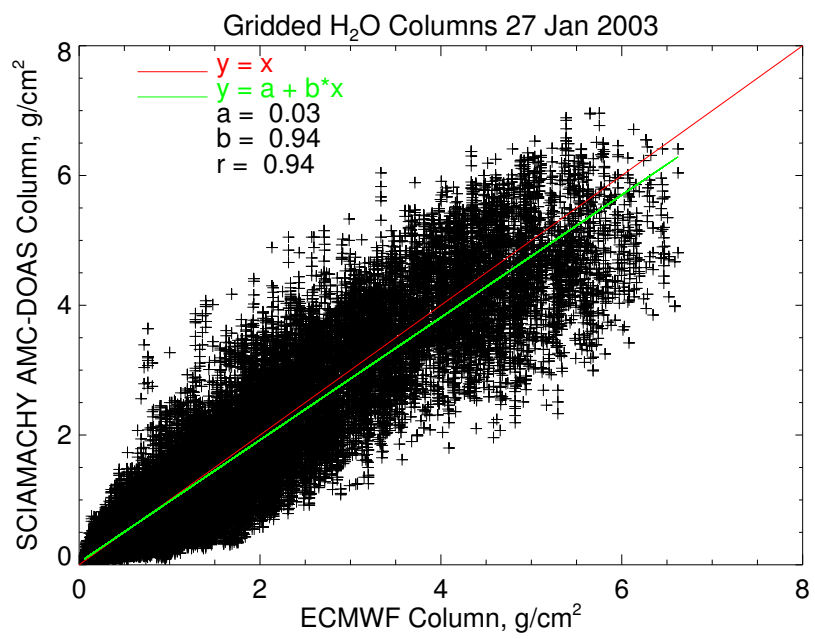

Fig. 12. Correlation between ECMWF and SCIAMACHY/AMCDOAS water vapour total vertical columns for 27 January 2003. Red line: 1:1 correlation. Green line: Linear fit. The resulting linear Pearson's correlation coefficient $r$ is also specified.

Figure 11 shows a global map of the ECMWF water vapour data, which in fact agrees well with both SSM/I and SCIAMACHY results. As mentioned before, the resolution of the ECMWF data used is $1.5^{\circ} \times 1.5^{\circ}$ which is slightly coarser than for SSM/I and SCIAMACHY. However, for the statistical analysis described here it is sufficient to match each ECMWF grid point to (up to) nine SSM/I or SCIAMACHY data points.

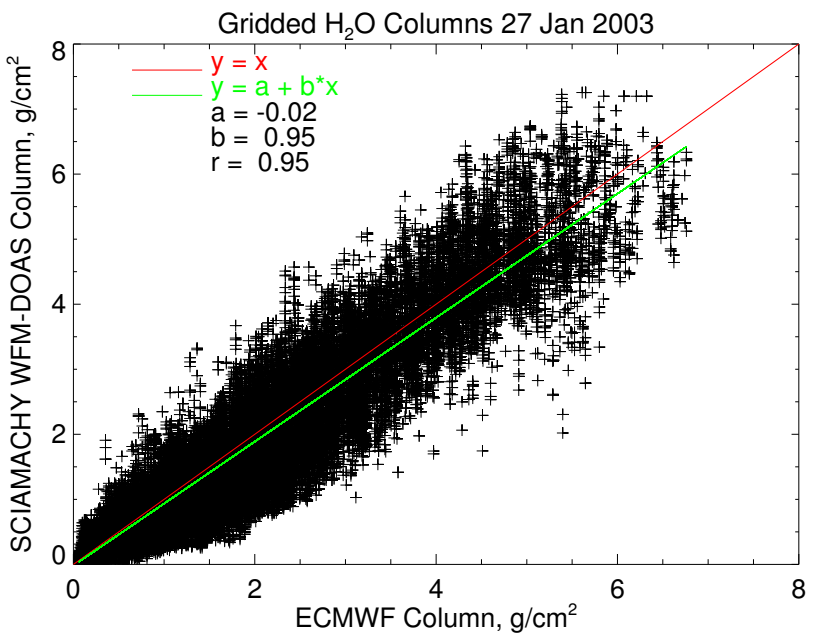

Fig. 13. Correlation between ECMWF and SCIAMACHY/WFMDOAS water vapour total vertical columns for 27 January 2003. Red line: 1:1 correlation. Green line: Linear fit. The resulting linear Pearson's correlation coefficient $r$ is also specified.

The correlation between the ECMWF data and the SCIAMACHY total water vapour column amounts are show in Fig. 12 for AMC-DOAS data and Fig. 13 for WFM-DOAS data. The agreement in both cases is very good. The Pearson's $r$ correlation is better than 0.94; there is almost no bias, and the slope of the fitted linear curve is 0.94 for AMCDOAS and 0.95 for WFM-DOAS. The scatter of the data is high but not much higher than for ocean scenes. Most of 
Table 6. Deviation of retrieved water vapour columns from reference data for different column intervals. The last line gives the average deviations for the complete columnar range from 0 to $7 \mathrm{~g} / \mathrm{cm}^{2}$.

\begin{tabular}{ccccccccc}
\hline $\begin{array}{c}\text { Column } \\
\text { Range } \\
\left(\mathrm{g} / \mathrm{cm}^{2}\right)\end{array}$ & \begin{tabular}{c} 
AMC-DOAS - SSM/I \\
\cline { 2 - 8 }$\left(\mathrm{g} / \mathrm{cm}^{2}\right)$
\end{tabular} & $\begin{array}{c}\text { Atd. Dev. } \\
\left(\mathrm{g} / \mathrm{cm}^{2}\right)\end{array}$ & $\begin{array}{c}\text { Aean Dev. } \\
\left(\mathrm{g} / \mathrm{cm}^{2}\right)\end{array}$ & $\begin{array}{c}\text { Std. Dev. } \\
\left(\mathrm{g} / \mathrm{cm}^{2}\right)\end{array}$ & $\begin{array}{c}\text { Mean Dev. } \\
\left(\mathrm{g} / \mathrm{cm}^{2}\right)\end{array}$ & $\begin{array}{c}\text { Std. Dev. } \\
\left(\mathrm{g} / \mathrm{cm}^{2}\right)\end{array}$ & $\begin{array}{c}\text { Mean Dev. } \\
\left(\mathrm{g} / \mathrm{cm}^{2}\right)\end{array}$ & $\begin{array}{c}\text { Std. Dev. } \\
\left(\mathrm{g} / \mathrm{cm}^{2}\right)\end{array}$ \\
\hline $0.00-1.00$ & -0.35 & 0.51 & -0.07 & 0.26 & -0.30 & 0.58 & -0.08 & 0.24 \\
$1.00-2.00$ & -0.17 & 0.44 & -0.09 & 0.47 & -0.21 & 0.43 & -0.18 & 0.46 \\
$2.00-3.00$ & -0.06 & 0.70 & 0.08 & 0.67 & -0.07 & 0.54 & -0.04 & 0.56 \\
$3.00-4.00$ & -0.08 & 0.75 & 0.12 & 0.88 & -0.03 & 0.54 & 0.07 & 0.64 \\
$4.00-5.00$ & -0.00 & 0.74 & 0.12 & 0.83 & -0.03 & 0.55 & 0.02 & 0.66 \\
$5.00-6.00$ & 0.53 & 0.61 & 0.59 & 0.68 & 0.30 & 0.63 & 0.40 & 0.67 \\
$6.00-7.00$ & 0.63 & 0.40 & 0.90 & 0.47 & 0.73 & 0.47 & 0.91 & 0.57 \\
\hline $0.00-7.00$ & -0.14 & 0.62 & -0.03 & 0.45 & -0.16 & 0.54 & -0.08 & 0.39 \\
\hline
\end{tabular}

the scatter can be attributed to the large temporal and spatial variability of water vapour.

\subsection{Statistical analysis}

For each of the comparisons described above a statistical analysis has been performed. For this purpose, all SCIAMACHY data shown in Figs. 9 to 13 have been binned into water vapour vertical column intervals from $0-1 \mathrm{~g} / \mathrm{cm}^{2}$ up to $6-7 \mathrm{~g} / \mathrm{cm}^{2}$. For each of these intervals and for each comparison the following quantities have been determined:

1. The mean deviation between the SCIAMACHY column and the reference column (either from SSM/I or ECMWF); this is a measure for systematic offsets between the data sets.

2. The standard deviation of the difference between the SCIAMACHY column and the reference column; this is a measure for the deviation between correlative data points. The results of this analysis are shown in Table 6.

The results for AMC-DOAS and WFM-DOAS are quite similar, although WFM-DOAS seems to perform slightly better especially for smaller columns, probably because the real atmospheric conditions are better adapted by the iterative approach. AMC-DOAS only uses one (tropical) reference atmosphere for the whole Earth, nevertheless the columns retrieved by this method agree remarkably good with both SSM/I and ECMWF data.

Smaller columns are typically underestimated, larger columns overestimated by SCIAMACHY. The agreement between the SCIAMACHY results and both SSM/I and ECMWF data is best in the columnar range from 2 to $5 \mathrm{~g} / \mathrm{cm}^{2}$ where the mean deviations vary between -0.08 and $0.12 \mathrm{~g} / \mathrm{cm}^{2}$. The maximum average deviation is $0.91 \mathrm{~g} / \mathrm{cm}^{2}$ at very high columns. Largest relative discrepancies occur for very small columns, especially when compared to SSM/I. The latter is partly caused by those extraordinarily high SSM/I values probably obtained over ice which have been mentioned before.

The standard deviation of the data sets is typically about $0.5 \mathrm{~g} / \mathrm{cm}^{2}$ and varies between about 0.4 and $0.8 \mathrm{~g} / \mathrm{cm}^{2}$. The scatter is quite independent from the water vapour column amount, although of course it becomes smaller for very small columns. This is in line with the assumption that most of the scatter is produced by the spatial and temporal variability of water vapour.

Both the AMC-DOAS and the WFM-DOAS results agree on average better with ECMWF data than with SSM/I data. This indicates that both methods are not only applicable over ocean scenes but also over land, and that they benefit from the enhanced signal over land caused by the higher albedo.

\section{Conclusions}

For the first time, global total water vapour column amounts have been retrieved from SCIAMACHY data in the spectral region around $700 \mathrm{~nm}$ using two different methods, AMCDOAS and WFM-DOAS. These methods have been successfully applied on GOME data in previous studies and have been adapted for the analysis of SCIAMACHY data. Both algorithms include inherent methods to assess the quality of the retrieved columns. Comparisons of the derived SCIAMACHY water vapour columns with corresponding SSM/I and ECMWF data have shown an excellent correlation for both methods. This is the case not only for ocean scenes but also over land, which is an advantage with respect to SSM/I. However, both methods compensate for a currently unexplained systematic deviation of $10 \%$ which needs further investigation. Looking at the slope of a fitted straight line, the average agreement between the different data sources is better than $5 \%$, irregardless of ground scene, although there is a significant scatter (in the order of $0.5 \mathrm{~g} / \mathrm{cm}^{2}$ ) in the data which can be mainly attributed to the high spatial and temporal variability of water vapour. The water vapour 
columns derived from SCIAMACHY measurements are typically slightly smaller than those of the correlative data sets; the mean deviation between SCIAMACHY and SSM/I data is about $0.15 \mathrm{~g} / \mathrm{cm}^{2}$; the mean deviation from ECMWF data is less than $0.1 \mathrm{~g} / \mathrm{cm}^{2}$.

Due to the currently reduced availability of consolidated SCIAMACHY data, the algorithms have up to now only been applied to a small amount of data. In this sense the promising results presented here are only valid for a rather limited time interval. However, first investigations using SCIAMACHY data for other days show similar results, and it is planned to extend the analysis range in further studies.

Therefore it can be concluded that both the AMC-DOAS and the WFM-DOAS method are able to retrieve reasonable total water vapour columns from SCIAMACHY data not only over ocean but also over land. The algorithms are reliable and in principle fast enough to allow for an operational processing and are thus good candidates for a future "visible water vapour" data product of SCIAMACHY which is currently under discussion.

Acknowledgements. SCIAMACHY data have been provided by ESA. SSM/I data have been provided by the Global Hydrology Resource Center (GHRC) at the Global Hydrology and Climate Center, Huntsville, Alabama. We thank the European Center for Medium Range Weather Forecasting (ECMWF) for providing us with analysed meteorological fields and our colleagues J. MeyerArnek and S. Dhomse for assistance in handling these data. This work has been funded by the BMBF via GSF/PT-UKF and DLRBonn and by the University of Bremen.

\section{References}

Bovensmann, H., Burrows, J. P., Buchwitz, M., Frerick, J., Noël, S., Rozanov, V. V., Chance, K. V., and Goede, A. H. P.: SCIAMACHY - Mission Objectives and Measurement Modes, J. Atmos. Sci., 56, 127-150, 1999.

Bovensmann, H., Ahlers, B., Buchwitz, M., Frerick, J., Gottwald, M., Hoogeveen, R., Kaiser, J., Kleipool, Q., Krieg, E., Lichtenberg, G., Mager, R., Meyer, J., Noël, S., Schlesier, A., Sioris, C., Skupin, J., v. Savigny, C., Wuttke, M. W., and Burrows, J. P.: SCIAMACHY in-flight instrument performance, in Proc. ENVISAT Calibration Review, ESTEC/Noordwijk, SP-520, published on CD, ISBN 92-9092-830-1, 2002.

Bovensmann, H., Buchwitz, M., Frerick, J., Hoogeveen, R., Kleipool, Q., Lichtenberg, G., Noël, S., Richter, A., Rozanov, A., Skupin, J., von Savignya, C., Wuttke, M. W., and Burrows, J. P.: SCIAMACHY on ENVISAT: In-flight optical performance and first results, in Remote Sensing of Clouds and the Atmosphere VIII, vol. 5235 of Proc. SPIE, in press, 2003.

Buchwitz, M. and Burrows, J. P.: Retrieval of $\mathrm{CH}_{4}, \mathrm{CO}$, and $\mathrm{CO}_{2}$ total column amounts from SCIAMACHY near-infrared nadir spectra: Retrieval algorithm and first results, in Remote Sensing of Clouds and the Atmosphere VIII, vol. 5235 of Proc. SPIE, in press, 2003.

Buchwitz, M., Rozanov, V. V., and Burrows, J. P.: A near infrared optimized DOAS method for the fast global retrieval of atmo- spheric $\mathrm{CH}_{4}, \mathrm{CO}, \mathrm{CO}_{2}, \mathrm{H}_{2} \mathrm{O}$, and $\mathrm{N}_{2} \mathrm{O}$ total column amounts from SCIAMACHY / ENVISAT-1 nadir radiances, J. Geophys. Res., 105, 15 231-15 246, 2000a.

Buchwitz, M., Rozanov, V. V., and Burrows, J. P.: A correlated-k distribution scheme for overlapping gases suitable for retrieval of atmospheric constituents from moderate resolution radiance measurements in the visible/near-infrared spectral region, J. Geophys. Res., 105, 15 247-15 262, 2000 b.

Buchwitz, M., Noël, S., Bramstedt, K., Rozanov, V. V., Bovensmann, H., Tsvetkova, S., and Burrows, J. P.: Retrieval of trace gas vertical columns from SCIAMACHY/ENVISAT nearinfrared nadir spectra: First preliminary results, Adv. Space Res., in press, 2003.

Burrows, J. P., Weber, M., Buchwitz, M., Rozanov, V., LadstätterWeißenmayer, A., Richter, A., de Beek, R., Hoogen, R., Bramstedt, K., Eichmann, K.-U., Eisinger, M., and Perner, D.: The Global Ozone Monitoring Experiment (GOME): Mission Concept and First Scientific Results, J. Atmos. Sci., 56, 151-175, 1999.

Casadio, S., Zehner, C., Pisacane, G., and Putz, E.: Empirical retrieval of the atmospheric air mass factor (ERA) for the measurement of water vapour vertical contenet using GOME data, Geophys. Res. Lett., 27, 1483-1486, 2000.

Coheur, P.-F., Clerbaux, C., Carleer, M., Fally, S., Hurtmans, D., Colin, R., Hermans, C., Vandaele, A. C., Barret, B., Mazière, M. D., and Backer, H. D.: Retrieval of atmospheric water vapor columns from FT visible solar absorption spectra and evaluation of spectroscopic databases, J. Quant. Spectr. Rad. Transf., 82, 133-150, 2003.

Dai, A., Wang, J., Ware, R. H., and Hove, T. V.: Diurnal variation in water vapor over North America and its implications for sampling errors in radiosonde humidity, J. Geophys. Res., 107 10.1029/2001JD000642, 2002.

Hess, M., Koepke, P., and Schult, I.: Optical properties of aerosols and clouds: The software package OPAC, Bulletin of the American Meteorological Society, 75, 831-844, 1998.

Kneizys, F., Abreu, L., Andrson, G., Chetwynd, J., Shettle, E., Berk, A., Bernstein, L., Robertson, D., Acharya, P., Rothman, L., Selby, J., Gallery, W., and Clough, S.: The MODTRAN 2/3 Report and LOWTRAN 7 Model, Tech. rep., Phillips Laboratory, Hanscom AFB, contract F19628-91-C-0132 with Ontar Corp., 1996.

Lang, R., Williams, J. E., van der Zande, W. J., and Maurellis, A. N.: Application of the Spectral Structure Parameterization technique: retrieval of total water vapor columns from GOME, Atmos. Chem. Phys., 3, 145-160, 2003.

Maurellis, A. N., Lang, R., van der Zande, W. J., Aben, I., and Ubachs, W.: Precipitable Water Vapor Column Retrieval from GOME Data, Geophys. Res. Lett., 27, 903-906, 2000.

Noël, S., Buchwitz, M., Bovensmann, H., Hoogen, R., and Burrows, J. P.: Atmospheric Water Vapor Amounts Retrieved from GOME Satellite Data, Geophys. Res. Lett., 26, 1841-1844, 1999.

Noël, S., Bovensmann, H., and Burrows, J. P.: Water vapour retrieval from GOME data including cloudy scenes, in Proc. ENVISAT/ERS Symposium, Gothenburg, SP-461, (published on CD, ISBN 92-9092-685-6), 2000.

Noël, S., Bovensmann, H., Wuttke, M. W., Burrows, J. P., Gottwald, M., Krieg, E., Goede, A. P. H., and Muller, C.: Nadir, limb, and 
occultation measurements with SCIAMACHY, Adv. Space Res., 29, 1819-1824, 2002a.

Noël, S., M.Buchwitz, Bovensmann, H., and Burrows, J. P.: Retrieval of total water vapour column amounts from GOME/ERS2 data, Adv. Space Res., 29, 1697-1702, 2002b.

Perner, D. and Platt, U.: Detection of Nitrous Acid in the Atmosphere by Differential Optical Absorption, Geophys. Res. Lett., 6, 917-920, 1979.

Rothman, L. S., Barbe, A., Benner, D. C., Brown, L. R., CamyPeyret, C., Carleer, M. R., Chance, K., Clerbaux, C., Dana, V., Devi, V. M., Fayt, A., Flaud, J.-M., Gamache, R. R., Goldman, A., Jacquemart, D., Jucks, K. W., Lafferty, W. J., Mandin, J.-Y., Massie, S. T., Nemtchinov, V., Newnham, D. A., Perrin, A., Rinsland, C. P., Schroeder, J., Smith, K. M., Smith, M. A. H., Tang, K., Toth, R. A., Auwera, J. V., Varanasi, P., and Yoshino, K.: The HITRAN molecular spectroscopic database: edition of 2000 including updates through 2001, J. Quant. Spectr. Rad. Transf., 82, 5-44, 2003.
Rozanov, V. V., Diebel, D., Spurr, R. J. D., and Burrows, J. P.: GOMETRAN: A Radiative Transfer Model for the Satellite Project GOME - The Plane Parallel Version, J. Geophys. Res., 102, 16 683-16 695, 1997.

Rozanov, V. V., Buchwitz, M., Eichmann, K.-U., de Beek, R., and Burrows, J. P.: SCIATRAN - a new radiative transfer model for geophysical applications in the $240-2400 \mathrm{~nm}$ spectral region: The pseudo-spherical version, Adv. Space Res., 29, 1831-1835, 2002.

Shettle, E. P. and Fenn, R. W.: Models of the aerosols of the lower atmosphere and the effects of humidity variations on their optical properties, Tech. rep., Air Force Geophys. Lab. AFGL, 1979.

Sierk, B., Solomon, S., Daniel, J. S., Portmann, R. W., Gutman, S. I., Langford, A. O., Holub, C. S. E. K. H., and Florek, S. V.: Field test of spectral line intensity parameters for tropospheric water vapor, J. Geophys. Res., 108, 4351, doi:10.1029/2002JD002985, 2003.

Wagner, T., Heland, J., Zöger, M., and Platt, U.: A fast $\mathrm{H}_{2} \mathrm{O}$ total column density product from GOME - Validation with in-situ aircraft measurements, Atmos. Chem. Phys., 3, 651-663, 2003. 